\title{
Targeted Screening Reveals High Numbers of Prediabetes and Diabetes Mellitus in Moshi, Tanzania
}

\author{
Christine Ludwig', Melanie Streicher ${ }^{2}$, Sandra D Habicht ${ }^{3}$, Mark E Swai ${ }^{4}$ and Michael B Krawinkel ${ }^{3 *}$ \\ ${ }^{1}$ Department of Nutrition and Food Sciences, Nutritional Epidemiology, University of Bonn, Germany \\ ${ }^{2}$ Institute for Biomedicine of Aging, Friedrich Alexander University Erlangen-Nurnberg, Germany \\ ${ }^{3}$ Institute of Nutritional Sciences, Justus Liebig University Giessen, Germany \\ ${ }^{4}$ Kilimanjaro Christian Medical Centre, Moshi, United Republic of Tanzania
}

\begin{abstract}
Objective: Chronic non-communicable diseases, such as type 2 diabetes mellitus, have become global major health problems. In the United Republic of Tanzania, previous studies showed diabetes prevalences ranging from $0.6 \%$ to $5.8 \%$ and of pre-diabetes, from $9.1 \%$ to $10.6 \%$. The pre-diabetes screening procedure described here was a targeted screening to recruit eligible subjects for a subsequent dietary intervention in Moshi, Tanzania.

Methods: The pre-diabetes screening procedure described here was used to identify subjects for a dietary intervention in Moshi, Tanzania. Main enrollment criteria for participants were fasting plasma glucose levels of 5.6$6.9 \mathrm{mmol} / \mathrm{L}(100-125 \mathrm{mg} / \mathrm{dL})$ on two days or on one day plus $\mathrm{HbA} 1 \mathrm{c}$ in the range of $5.7-7.5 \%(39-58 \% \mathrm{mmol} / \mathrm{mol})$, body mass index of $27-35 \mathrm{~kg} / \mathrm{m}^{2}$, and age between $30-65$ years.

Results: Through pre-screening of a total of 1,256 people were examined for BMI and age; 382 people were further screened for markers of pre-diabetes. Following ADA and WHO-criteria, 51\% (73\%) had normal, 35\% $(13 \%)$ pre-diabetic, and $15 \%(15 \%)$ diabetic fasting plasma glucose levels. Among the individuals with hyperglycemia indicating diabetes mellitus, $60 \%$ were unaware of their condition. Applying ADA criteria for $\mathrm{HbA} 1 \mathrm{c}$ to all people, $42 \%$ had normal, $42 \%$ had pre-diabetic, and $16 \%$ had diabetic $\mathrm{HbA} 1 \mathrm{c}$ levels. Identified risk factors for increased fasting plasma glucose were age, waist circumference, body mass index, and a family history of diabetes mellitus.

Conclusion: Although the screening sample was not representative for the study area's population and not diagnostic, the high rates of pre-diabetic and diabetic fasting plasma glucose levels are of public health concern. The low concordance between the data for FPG and $\mathrm{HbA} 1 \mathrm{c}$ requires further investigation, as well as the discrepancy between $\mathrm{ADA}$ and $\mathrm{WHO}$ definitions of impaired fasting glucose.
\end{abstract}

Keywords: Prediabetes, diabetes mellitus, awareness, prevalence, screening, fasting plasma glucose, HbAlc, body mass index, waist circumference, family history

Abbreviations: BP: Blood Pressure; FPG: Fasting Plasma Glucose ;IFG: Impaired Fasting Glucose; IGT: Impaired Glucose Tolerance; OGTT: Oral Glucose Tolerance Test; RBG: Random Blood Glucose; SUR: Seemingly Unrelated Regression

\section{Introduction}

Chronic non-communicable diseases, such as type 2 diabetes mellitus, have become major health problems in high-income countries for decades but are also spreading fast in low- and middle-income countries [1]. Type 2 diabetes mellitus is a disease partially linked to overweight and obesity as well as to low physical activity [1-3]. In the age group of 20-79 years, the current estimate of global prevalence of diabetes is $8.8 \%$, with an expected increase to $10.4 \%$ by 2040 . In SubSaharan Africa, the current estimate of the regional prevalence is $3.2 \%$ with an expected increase to $4.2 \%$ by 2040 . It is assumed that almost $67 \%$ of diabetes patients are still undiagnosed in this region [4]. In Sub-Saharan Africa as well as worldwide, $90 \%$ of all cases are type 2 diabetes mellitus [5]. The International Diabetes Federation estimated Tanzania's national diabetes prevalence to be $2.3 \%$ in 2011 [6], $7.8 \%$ in 2013 [7], and $3.5 \%$ in 2015 [4]. Other studies showed diabetes rates ranging from $0.6 \%$ to $5.8 \%[8,9]$. Prevalence of pre-diabetes, defined as impaired glucose tolerance (IGT), were $10.6 \%$ in 2011 [6] and $9.08 \%$ in 2013 [7]. Used cut-offs for IGTs are 7.8 to $11.0 \mathrm{mmol} / \mathrm{L}$ (140 to 199 $\mathrm{mg} / \mathrm{dL}$ ) for 2-hour glucose levels measured during an oral glucose tolerance test (OGTT) with a $75 \mathrm{~g}$ glucose load $[10,11]$. Pre-diabetes can also be defined as impaired fasting plasma glucose (IFG) defined by the World Health Organization (WHO) [10] and the American Diabetes Association (ADA) [11] using cut-offs of 6.0 to $6.9 \mathrm{mmol} / \mathrm{L}$ (110 to $125 \mathrm{mg} / \mathrm{dL}$ ) and 5.6 to $6.9 \mathrm{mmol} / \mathrm{L}(100$ to $125 \mathrm{mg} / \mathrm{dL})$, respectively. The use of $\mathrm{HbAlc}$ to classify pre-diabetes is not universally recommended. The ADA recommends HbAlc- cut-offs of 5.7\% 86 to $6.4 \%$ (39 to $46 \mathrm{mmol} / \mathrm{mol}$ ) for the pre-diabetic stage [11]. Pre-diabetes can be detected during screening at clinical visits or public screening activities in communities. Different screening methods may be applied individually or in combination, depending on the purpose and scope of the screening. Such methods include questionnaires, measurement of fasting plasma glucose FPG, random blood glucose (RBG), HbAlc, or conduction of an OGTT. Screening can be performed in stages, starting, for example, with using a questionnaire to assess risk factors, followed by an assessment of the glycemic status of those with elevated risk factor scores. The ADA recommends a screening every three years for

*Corresponding author: Prof. Krawinkel MB, Institute of Nutritional Sciences, Justus-Liebig University, Wilhelmstr. 20, D-35392 Giessen, Germany, Tel: +49 641 9939034; Email: Michael.Krawinkel@uni-giessen.de

Received December 08, 2016; Accepted January 03, 2017; Published January 09, 2017

Citation: Ludwig C, Streicher M, Habicht SD, Swai ME, Krawinkel MB (2017) Targeted screening reveals high numbers of prediabetes and diabetes mellitus in Moshi, Tanzania. J Diabetes Metab 8: 720. doi: 10.4172/2155-6156.1000720

Copyright: $\odot 2017$ Ludwig C, et al. This is an open-access article distributed under the terms of the Creative Commons Attribution License, which permits unrestricted use, distribution, and reproduction in any medium, provided the original author and source are credited. 
asymptomatic adults older than 45 years of age, and for younger adults with a BMI $\geq 25 \mathrm{~kg} / \mathrm{m}^{2}$ who have at least one additional risk factor such as low physical activity or a first-degree family member with diabetes [12]. However, some argue that screening for diabetes mellitus and prediabetes is not justifiable [13], as it does not meet all criteria for disease screening $[14,15]$. The pre-diabetes screening procedure described here was a targeted screening to identify eligible subjects for a subsequent dietary intervention in Moshi, Tanzania. This paper addresses the screening for prediabetes only. It further aims at providing insights into the challenges of diabetes-related health problems in East Africa.

\section{Methods}

The aim of the screening was to identify otherwise healthy pre-diabetics between 30 and 65 years of age by the following the criteria: Fasting plasma glucose of 5.6-6.9 mmol/L (100-125 mg/dL) on two days or on one day plus $\mathrm{HbA} 1 \mathrm{c}$ in the range of $5.7-7.5 \%$ (39-58\% $\mathrm{mmol} / \mathrm{mol}$ ). To increase the chance of identifying individuals with pre diabetic glucose levels and without co-morbidities, a body mass index (BMI) between $27-35 \mathrm{~kg} / \mathrm{m}^{2}$ was chosen as an inclusion criterion for the current screening. Blood pressure (BP) between 90/60-160/110 $\mathrm{mmHg}$ was chosen to exclude individuals with low blood pressure. The upper cut-off values were chosen, as a previous assessment in the area detected generally high blood pressure values in the respective age group. The remaining inclusion criteria were waist circumference (WC) $>80 \mathrm{~cm}$ for women and $>90 \mathrm{~cm}$ for men, absence of any diagnosed disease and of any regular medication, no heavy alcohol consumption, no pregnancy, and no breastfeeding. The study-related $\mathrm{HbAlc}$ upper limit exceeded ADA recommended cut-offs for pre-diabetes. During the screening, $\mathrm{HbA1c}$ levels were indicating notably higher glycemia than the corresponding FPG levels. The use of higher cut-offs in the HbAlc criterion was approved by the institutional review boards of the National Institute for Medical Research (NIMR) and Kilimanjaro Christian Medical College. During 2013/2014, HbAlc cartridges were recalibrated by HemoCue which resulted in lower readings compared to old cartridges. However, a conversion factor was not provided, and was instead calculated by comparing old and new cartridges analyzed by the HemoCue 501 analyzer (HemoCue $\mathrm{GmbH}$, Germany and another $\mathrm{HbAlc}$ point-of-care analyzer (DCA Vantage Analyzer, Siemens, Germany). Corrected HbAlc levels are presented in the current analysis. During the screening process, eligibility criteria were based on uncorrected $\mathrm{HbAlc}$ values.

\section{Study Area}

The recruitment procedure including pre-screening and screening for pre-diabetic participants was conducted in Moshi Urban District, one of the six districts of the Kilimanjaro Region in northern Tanzania. In 2012, the Kilimanjaro Region had a population of 1,640,087 [16]. Moshi Municipality, the capital of Moshi Urban District, is divided into 21 wards [17] of which seven (Longuo, Rau, Karanga, Mawenzi, Majengo, Mji Mpya, Njoro, Pasua) were chosen as pre-screening areas due to their proximity to the screening facility in Longuo or due to their use in previous studies. Screening took place at the Kilimanjaro Clinical Research Institute (KCRI), which is closely associated with the Kilimanjaro Christian Medical Centre (KCMC) [18].

\section{Recruitment Procedure}

Pre-screening took place between April and October 2013 at 16 different settings in Moshi and addressed the following groups and institutions: people reached through radio announcements, doctors and nurses at KCMC, three Lutheran and four Roman Catholic churches, one convent, two banks, teachers at two primary schools, staff and lecturers at one university, one mosque, one police academy, one revenue authority, and KCRI. In addition, individuals from the wards Njoro and Pasua were invited who had been identified as pre-diabetics in a previous study. During pre-screening, information was provided about the procedures, rationale and aims. Data on sex, age, BMI, and BP as well as contact information were collected from interested volunteers. In the early stages of the study, body weight was measured with an analogue scale and height with an elastic measurement tape fixed to a straight wall. In the later stages, body weight was measured with a digital scale (Seca 877 Germany) and portable stadiometer (Seca 217, Germany). BMI was calculated as bodyweight in $\mathrm{kg}$ divided by the square of body height in $\mathrm{m}$. While seated, each participant's BP was measured on the left arm using a Visomat Double Comfort blood pressure cuff (range: systolic 50-250 $\mathrm{mmHg}$, diastolic $40-150 \mathrm{mmHg}$, Uebe Medical GmbH, Germany). All measurements were performed once. BMI and BP values were categorized according to WHO guidelines [19,20] and American Heart Association [21] guidelines, respectively. All identified participants with relevant BMI, BP and age were invited to the screening. To facilitate logistics and evaluation processes, people pre-screened at KCRI were invited to participate in all pre-screening and screening measurements at the same day.

The screening and all other data collection took place at the KCRI between July and October 2013. Appointments were scheduled between 7:30 and 10:30 a.m. Participants were instructed to fast overnight before the examination. A questionnaire-based interview was performed to assess socioeconomic and health related data. Data on body weight and height, waist and hip circumferences, BP, FPG, and HbAlc were collected according to the following procedures. Body weight was measured using a digital scale (Seca 877, Germany). Body height was measured using a portable stadiometer (Seca 217, Germany) according to FANTA protocol [22], with participants dressed in light clothing and without shoes. Measurements were performed only once. Waist circumference and hip circumference (data not shown) were measured twice using a retractable measurement band according to STEPS Surveillance [23]. If the difference between the two measurements was greater than $1 \mathrm{~cm}$, a third measurement was performed. The mean of the measurements was then recorded. After sitting for $5 \mathrm{~min}$, blood pressure was measured once on the left arm using a Visomat Double Comfort blood pressure cuff.

Capillary blood samples were obtained from a dry fingertip after disinfection using one disposable lancet for each person. FPG was measured using Accu-Chek Aviva blood glucose meters (Roche Diagnostics, Switzerland). Glycosylated hemoglobin was measured using a HemoCue 501 analyzer (HemoCue ${ }^{\circ} \mathrm{GmbH}$, Germany). Both appliances are point-of-care devices and results were available after a few seconds for FPG and after five minutes for HbAlc. Participants with high glucose levels were advised to go to their nearest clinic for further medical consultation.

All participants were reimbursed for their traveling expenses and given a record chart of their data, reference ranges, and a small snack. If requested, participants were given counseling for nutrition and physical activity as part of a healthy lifestyle.

\section{Ethics}

The study protocol was approved by the Medical Research Coordinating Committee of the National Institute of Medical Research, Tanzania, the Tanzanian Food and Drug Authority, and the institutional review boards of the Kilimanjaro Christian Medical 
College, and the Faculty of Medicine at Justus-Liebig-University, Giessen, Germany and the Regional Medical Office in Moshi. All prescreened and screened participants gave verbal consent to participate in the recruitment procedure and were informed about their right to withdraw at any time without any negative consequences for them.

\section{Statistical Analysis}

Data entry and analysis were performed using Microsoft Excel, 2013 SPSS version 22, and Stata version 14. Variables are expressed as frequencies or as median and interquartile range. Only WC was consistent with a normal distribution and described by a mean and standard deviation. A Mann-Whitney U-test was used to identify differences in continuous variables between male and female participants. A Chi squared test was used to identify differences between categories in categorical variables.

Among the pre-screening sample, Spearman's $\rho$ was calculated to assess correlations. Concordance between FPG and HbAlc data indicating hyperglycemia was calculated using Krippendorff's $\alpha$ [24]. Hyperglycemia was defined as FPG $\geq 5.6 \mathrm{mmol} / \mathrm{L}$ ( $\geq 100 \mathrm{mg} / \mathrm{dL}$ ) or $\mathrm{HbAlc} \geq 5.7 \%$ ( $\geq 39 \mathrm{mmol} / 216 \mathrm{~mol})$. Among the screening sample, a non-linear model with seemingly unrelated regression (SUR) [25] was computed to analyze effects of age on FPG, HbAlc, and BP, as well as to analyze effects of WC and BMI on the dependent variables. Age was controlled for gender; WC and BMI were controlled for age and gender. If necessary, the quadric variation of the centered independent variable was used. FPG, $\mathrm{HbAlc}$, and BP were log transformed (LN) prior to analyses. For these particular models, participants who take medication regularly or were pregnant were excluded. Statistical significance of different associations was assumed at a level of $p<0.05$ as the individuals identified were regarded as sample of the screened subpopulation.

\section{Results}

A total of 1,256 people were pre-screened. Most people attended pre-screening after church services. The highest rates of eligible BMI and age were found among office workers and teachers, Table 1. Median BMI (Q25;Q75) was $27.5 \mathrm{~kg} / \mathrm{m}^{2}(24.1 ; 31.3)$, median age was 47.0 years $(37.0 ; 55.0)$, median systolic $\mathrm{BP}$ was $125.0 \mathrm{mmHg}(114.0 ; 142.0)$, and median diastolic BP was $83.0 \mathrm{mmHg}(76.0 ; 91.0)$. About $30 \%$ of participants had arterial hypertension, Figure 1. People with high BP values were directed to go to their nearest health facility for further medical consultation. As shown in Table 2, median BMI increased across age groups until the age of 60 years. The majority of the pre-screened participants were overweight or obese, Figure 2, likely because the research team stated that it was seeking participants with an increased body weight. Systolic BP increased across age groups, reaching the highest median in the oldest age group. Diastolic BP increased up to the age group of 50-59 years. Age was correlated with systolic BP $(r=0.371)$ and diastolic BP $(r=2400.207)$. BMI was correlated with systolic BP ( $r$ $=0.144)$ and diastolic BP $(r=0.244)$. Systolic BP was highly correlated with diastolic BP $(r=0.724)$. All correlations were significant at the level of $p<0.001$. Systolic and diastolic BP was significantly higher in obese participants than in normal-weight participants $(\mathrm{U}=52793, \mathrm{z}=4.833$, $\mathrm{p}<0.001, \mathrm{r}=0.178 ; \mathrm{U}=45781, \mathrm{z}=7.296, \mathrm{p}<0.001, \mathrm{r}=0.270$, respectively). There was no difference between obese and overweight and between overweight and normal weight participants. Through pre-screening a total of 382 people were found eligible according to their age and BMI and therefore qualified for further screening. Based on ADA (WHO) FPG-criteria, 51\% (73\%) had normal, 35\% (13\%) had pre-diabetic, 249 and 15\% (15\%) had diabetic FPG levels. Among the latter group, $60 \%$ were unaware of their high glucose levels. Among diagnosed diabetics $(\mathrm{n}=26), 50 \%$ were on prescribed medication. However, their median FPG and $\mathrm{HbAlc}$ values were higher compared to cases in which diabetes status was unknown Table 3. According to ADA criteria for HbAlc, $42 \%$ had normal, $42 \%$ had pre-diabetic, and $16 \%$ had diabetic $\mathrm{HbAlc}$ levels. In the following, only the corrected $\mathrm{HbAlc}$ will bepresented. Concordance of dysglycemia between FPG and HbAlc measures was $68 \%$, with a Krippendorff's a of 0.351 indicating low reliability. Rates of hyperglycemia were higher according to HbAlc- than FPGdata. Regarding concordance of HbAlc and FPG in identifying the glycemic status, $62 \%$ were in the same criteria (31\% both normal, $20 \%$ both pre-diabetic, and $11 \%$ both diabetic). Nineteen percent showed pre-diabetic $\mathrm{HbA} 1 \mathrm{c}$, but normal FPG, and $12 \%$ pre-diabetic FPG, but normal HbAlc. In $7 \%$ other discordant combinations were found. The highest rate of concordance was observed in the diabetic category. Fourty-one percent of all screened participants had hypertension, defined by a systolic or diastolic BP meeting at least the state-I criteria, i.e. at least systolic BP mm Hg 140-159 or diastolic BP 90-99 mm Hg. Of these, $33 \%$ had previously been diagnosed with hypertension, and one third of them were taking medication. The remaining $67 \%$ were unaware of their arterial hypertension.

There was an increase in median BP and FPG values across age groups until 50-55 and 55-59 years, respectively, Table 4. Regarding undiagnosed diabetes, no clear trend was seen. Waist circumference, $\mathrm{BP}$, and prevalence of hypertension increased from normoglycemic over pre-diabetic to diabetic groups, Table 5. In the diabetes group, the highest percentage of family members with diabetes was found. Table 6 shows the results of the non-linear model with seemingly unrelated regression (SUR). In this model, the effect of age on systolic BP was stronger than on FPG and HbAlc. BMI and waist circumference had a higher effect on FPG and HbAlc than on BP. Waist circumference showed a linear association with the dependent variables, whereas $\mathrm{BMI}$ showed a non-linear association. However, overall $\mathrm{R}^{2}$ values were relatively low, with $\mathrm{R}^{2}$ ranging between 0.184 and 0.248 . Correlations of dependent variables are shown in Table 7. As expected, systolic B P was highly correlated with diastolic BP (0.804), and FPG with HbA1c (0.847). Systolic BP showed a medium, and diastolic BP a low, correlation with FPG and HbAlc,.

After screening for the defined inclusion and exclusion criteria for the dietary intervention study, 74 people could be identified. Two common exclusion factors for people who met the pre-diabetes criterion were having high BP and taking regular medication. Overall,

\begin{tabular}{|c|c|c|c|c|c|}
\hline $\begin{array}{c}\text { Pre-screening } \\
\text { site }\end{array}$ & $\begin{array}{c}\text { Pre-screened } \\
\mathbf{n}\end{array}$ & \multicolumn{2}{|c|}{$\begin{array}{c}\text { People meeting BMI \& } \\
\text { age criteria } \\
\mathbf{n}\end{array}$} & \multicolumn{3}{|c|}{$\begin{array}{c}\text { Attended } \\
\text { screening }\end{array}$} \\
\hline Bank & 35 & 21 & 60.0 & 1 & 4.7 \\
\hline Churches & 595 & 227 & 38.2 & 131 & 57.7 \\
\hline Convent & 13 & 6 & 46.2 & 4 & 66.7 \\
\hline Mosque & 40 & 12 & 30.0 & 7 & 58.3 \\
\hline $\begin{array}{c}\text { Primary } \\
\text { schools }\end{array}$ & 62 & 31 & 50.0 & 22 & 71.0 \\
\hline Police academy & 90 & 42 & 46.7 & 17 & 40.5 \\
\hline $\begin{array}{c}\text { Revenue } \\
\text { authority }\end{array}$ & 38 & 29 & 76.3 & 19 & 65.5 \\
\hline University & 15 & 10 & 66.7 & 10 & 100 \\
\hline Total outside & $\mathbf{8 8 8}$ & $\mathbf{3 7 8}$ & $\mathbf{4 2 . 5}$ & $\mathbf{2 1 1}$ & $\mathbf{5 5 . 8}$ \\
\hline $\begin{array}{c}\text { Total inside } \\
\text { KCRI }\end{array}$ & 368 & 171 & 46.6 & 171 & 100 \\
\hline Overall total & $\mathbf{1 , 2 5 6}$ & $\mathbf{5 4 9}$ & $\mathbf{4 3 . 7}$ & $\mathbf{3 8 2}$ & $\mathbf{6 9 . 6}$ \\
\hline
\end{tabular}

Table 1: Pre-screening sites and subsequent screening attendance rates. 
Citation: Ludwig C, Streicher M, Habicht SD, Swai ME, Krawinkel MB (2017) Targeted screening reveals high numbers of prediabetes and diabetes mellitus in Moshi, Tanzania. J Diabetes Metab 8: 720. doi: 10.4172/2155-6156.1000720

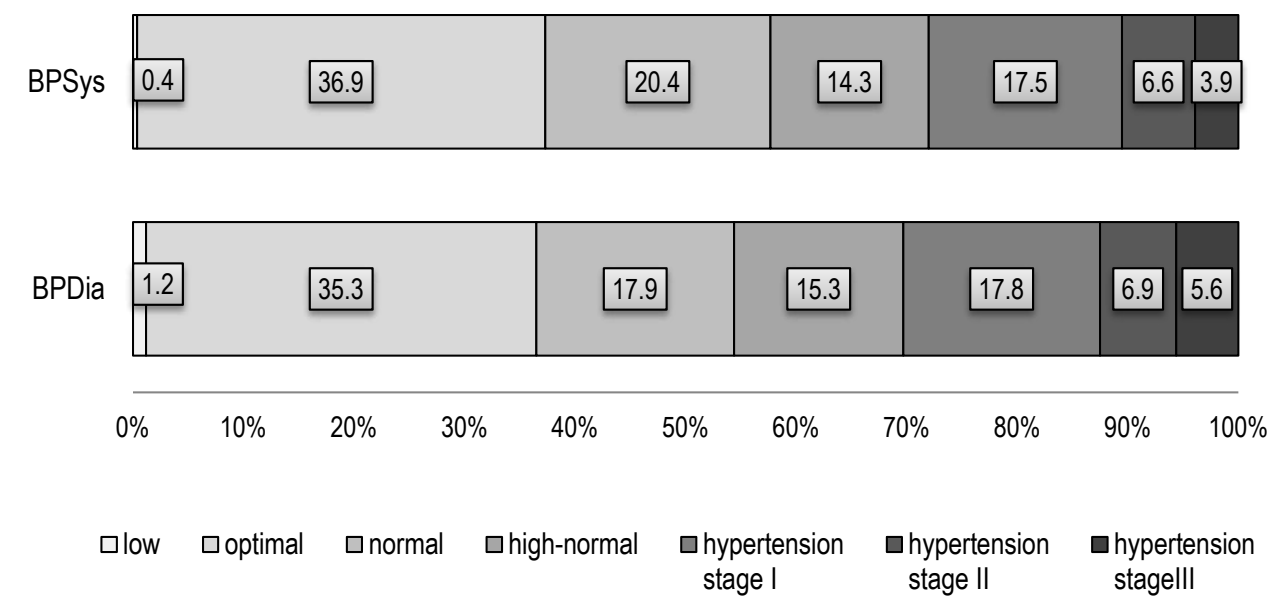

Figure 1: Classification of systolic $(n=1218)$ and diastolic $(n=1217)$ blood pressure (pre-screening).

\begin{tabular}{|c|c|c|c|c|c|c|c|c|}
\hline Variable / Age & $15-19 n=9$ & $20-29 n=96$ & $30-39 n=237$ & $40-49 n=316$ & $50-59 n=322$ & $60-69 n=124$ & $70-79 n=26$ & $\geq 0 n=10$ \\
\hline Body mass index $\left[\mathrm{kg} / \mathrm{m}^{2}\right]$ & $\begin{array}{c}20.8 \\
21.2 ; 27.7\end{array}$ & $\begin{array}{c}24.9 \\
20.9 ; 27.7\end{array}$ & $\begin{array}{c}27.8 \\
20.9 ; 27.7\end{array}$ & $\begin{array}{c}29.3 \\
25.7 ; 32.5\end{array}$ & $\begin{array}{c}28.6 \\
25.7 ; 31.8\end{array}$ & $\begin{array}{c}27.3 \\
22.8 ; 30.5\end{array}$ & $\begin{array}{c}24.9 \\
21.6 ; 28.9\end{array}$ & $\begin{array}{c}23.8 \\
21.2 ; 31.0\end{array}$ \\
\hline $\begin{array}{l}\text { Systolic blood pressure } \\
{[\mathrm{mmHg}]}\end{array}$ & $\begin{array}{c}106.0 \\
96.5 ; 121.0\end{array}$ & $\begin{array}{c}116.0 \\
107.5 ; 125.8\end{array}$ & $\begin{array}{c}120.2 \\
109.0 ; 129.0\end{array}$ & $\begin{array}{c}124.0 \\
114.0 ; 137.0\end{array}$ & $\begin{array}{c}134.0 \\
120.0 ; 149.0\end{array}$ & $\begin{array}{c}137.0 \\
120.0 ; 152.0\end{array}$ & $\begin{array}{c}143.5 \\
123.3 ; 163.0\end{array}$ & $\begin{array}{c}154.0 \\
141.0 ; 162.5\end{array}$ \\
\hline $\begin{array}{l}\text { Diastolic blood pressure } \\
{[\mathrm{mmHg}]}\end{array}$ & $\begin{array}{c}70.0 \\
64.0 ; 74.5\end{array}$ & $\begin{array}{c}77.5 \\
71.0 ; 82.8\end{array}$ & $\begin{array}{c}81.0 \\
74.0 ; 89.9\end{array}$ & $\begin{array}{c}87.0 \\
78.0 ; 92.0\end{array}$ & $\begin{array}{c}84.0 \\
79.9 ; 95.0\end{array}$ & $\begin{array}{c}84.0 \\
76.0 ; 93.0\end{array}$ & $\begin{array}{c}84.0 \\
78.0 ; 94.0\end{array}$ & $\begin{array}{c}70.0 \\
68.0 ; 95.5\end{array}$ \\
\hline
\end{tabular}

Table 2: Body mass index and blood pressure according to age group of the pre-screening sample $n=1,140$ (median \& IQR).

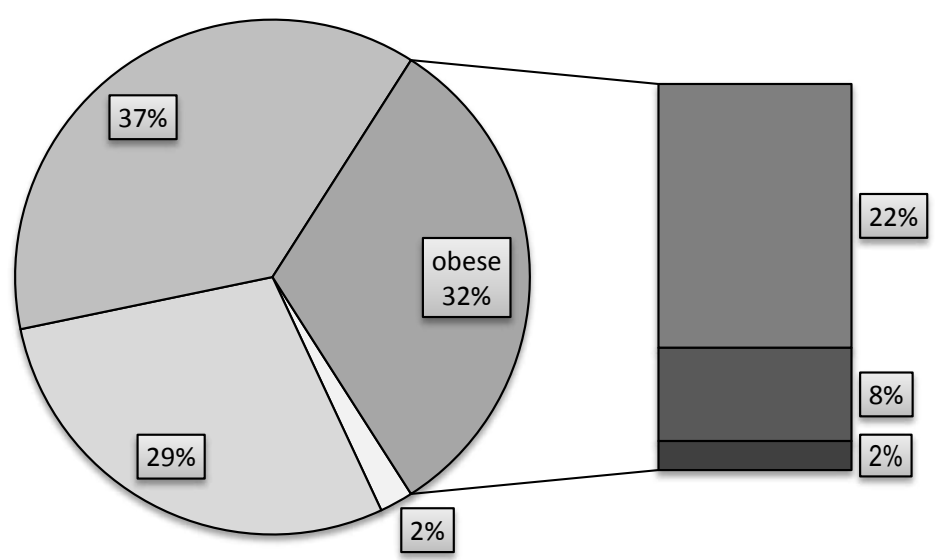

Figure 2: Classification of body mass index in the pre-screening sample, $n=1,252$.

the recruitment rate was $5 \%$ starting from the pre-screening phase and $16 \%$ starting from the screening phase (based on BMI and age).

\section{Discussion}

Screening for pre-diabetic volunteers was divided into two stages, a pre-screening phase and a screening phase, and was communicated via different channels. Due to word-of-mouth communication, $26 \%$ of pre-screened participants were pre-screened without prior attendance at information sessions, but were instead referred by already-prescreened people. In the pre-screening sample, rates of overweight and obesity were $37 \%$ and $32 \%$, respectively. However, as people with increased body weight were encouraged to participate in the recruitment procedure, relatively high rates of overweight and obesity were expected. In the most recent Tanzanian Demographic Health Survey (TDHS) of $2010,35 \%$ and $24 \%$ of women in the Kilimanjaro
Region were overweight or obese, respectively. The TDHS did not report any data for men [26]. As obesity is linked to an increased risk of chronic non-communicable diseases and negative outcomes [27], the high rates of obesity, especially of classes two and three in the current study, are a major health threat for that area. In the current study, obese participants had significantly higher BP values than normal-weight participants. Although sex was not recorded during the pre-screening, an subgroup analysis showed that women were three times more likely to be obese than male participants. This relation was also seen in a population study conducted in Mwanza District, where the obesity prevalence of women was $22 \%$ and that of men $7 \%$ in town settings [8]. In the data set of our study, a BMI in the overweight and obese ranges was more common among office workers and teachers than among people pre-screened at religious institutions. This may be linked to a more sedentary lifestyle due to jobs with low physical activity [28]. Vice 
Citation: Ludwig C, Streicher M, Habicht SD, Swai ME, Krawinkel MB (2017) Targeted screening reveals high numbers of prediabetes and diabetes mellitus in Moshi, Tanzania. J Diabetes Metab 8: 720. doi: 10.4172/2155-6156.1000720

Page 5 of 9

\begin{tabular}{|c|c|c|c|}
\hline Group & All $n=382$ & Female $n=264$ & Male $n=118$ \\
\hline Mean Age [years] & 47.5 & 48 & 45.0 \\
\hline Smoking [yes] [\%] & 2 & 0.4 & 6 \\
\hline Alcohol [yes] [\%] & 48 & 47 & 51 \\
\hline \multicolumn{4}{|l|}{ Education } \\
\hline completed primary [\%] & 36 & 39 & 47 \\
\hline completed secondary [\%] & 19 & 18 & 36 \\
\hline college [\%] & 36 & 31 & 19 \\
\hline Reporting disease [\%] & 36 & 36 & 36 \\
\hline Regular medication [\%] & 22 & 24 & 19 \\
\hline Mean Body mass index $\left[\mathrm{kg} / \mathrm{m}^{2}\right]$ & 29.9 & 30.7 & 28.3 \\
\hline Mean waist circumference $[\mathrm{cm}]$ & 94.2 & 92.4 & 98.0 \\
\hline Diabetic family member [\%] & 26 & 29 & 19 \\
\hline Mean Fasting plasma glucose $[\mathrm{mmol} / \mathrm{L}]$ & 5.5 & 5.5 & 5.6 \\
\hline normal fasting plasma glucose [\%] & 51 & 54 & 44 \\
\hline pre-diabetic fasting plasma glucose [\%] & 35 & 32 & 42 \\
\hline diabetic FPG [\%] & 14 & 14 & 15 \\
\hline undiagnosed diabetic FPG [\%] & 62 & 66 & 53 \\
\hline Dysglycemia [\%] & 49 & 46 & 56 \\
\hline HbA1c $[\%,(\mathrm{mmol} / \mathrm{mol})]$ & $5.7(39)$ & $5.7(39)$ & $6.0(42)$ \\
\hline normal & $42(70)$ & $45(76)$ & $37(58)$ \\
\hline pre-diabetic & $42(14)$ & $40(9)$ & $46(25)$ \\
\hline diabetic & $16(16)$ & $15(15)$ & $17(17)$ \\
\hline Mean Systolic blood pressure [mmHg] & 128.0 & 127.0 & 129.0 \\
\hline Mean Diastolic blood pressure [mmHg] & 86.0 & 86.0 & 87.0 \\
\hline Overall arterial hypertension [\%] & 41 & 41 & 40 \\
\hline Undiagnosed arterial hypertension [\%] & 68 & 65 & 71 \\
\hline
\end{tabular}

Footnote: If not otherwise specified, data are expressed as median and interquartile range; waist circumference is presented as mean and SD; glycemic status based on fasting plasma glucose (FPG) is shown using ADA and WHO (shown in parantheses) criteria; dysglycemia was defined by FPG $\geq 5.6 \mathrm{mmol} / \mathrm{L}$ (ADA) or $\geq 6.1 \mathrm{mmol} / \mathrm{L}$ (WHO); HbA1c is shown using ADA criteria; hypertension was defined by having at least one value in stage I, II, or III according to American Heart Association criteria.

Table 3: Overall characteristics of screening participants (including participants with reported diseases and use of medication).

\begin{tabular}{|c|c|c|c|c|c|c|c|}
\hline $\begin{array}{l}\text { Age group } \\
\text { Variable }\end{array}$ & $30-34 n=34$ & $35-39 n=52$ & $40-44 n=69$ & $45-49 n=72$ & $50-54 n=76$ & $55-59 n=57$ & $\geq 60 n=27$ \\
\hline Body mass index $\left[\mathrm{kg} / \mathrm{m}^{2}\right]$ & $\begin{array}{c}29.2 \\
28.3 ; 32.2\end{array}$ & $\begin{array}{c}29.2 \\
27.8 ; 32.0\end{array}$ & $\begin{array}{c}30.2 \\
28.0 ; 32.1\end{array}$ & $\begin{array}{c}30.8 \\
28.5 ; 32.8\end{array}$ & $\begin{array}{c}29.7 \\
28.2 ; 32.0\end{array}$ & $\begin{array}{c}30.2 \\
28.0 ; 31.5\end{array}$ & $\begin{array}{c}30.7 \\
28.1 ; 32.6\end{array}$ \\
\hline Waist circumference $[\mathrm{cm}]$ & $91.9(7.9)$ & $92.3(7.1)$ & $93.8(7.7)$ & $95.4(7.0)$ & $95.4(7.0)$ & $94.2(6.0)$ & $94.1(7.2)$ \\
\hline $\begin{array}{l}\text { Fasting plasma glucose } \\
{[\mathrm{mmol} / \mathrm{L}]}\end{array}$ & $\begin{array}{c}5.3 \\
4.7 ; 5.6\end{array}$ & $\begin{array}{c}5.3 \\
4.8 ; 5.6\end{array}$ & $\begin{array}{c}5.4 \\
5.0 ; 6.1\end{array}$ & $\begin{array}{c}5.6 \\
5.1 ; 6.1\end{array}$ & $\begin{array}{c}5.8 \\
5.2 ; 6.6\end{array}$ & $\begin{array}{c}5.6 \\
5.1 ; 6.8\end{array}$ & $\begin{array}{c}5.7 \\
5.3 ; 6.2\end{array}$ \\
\hline normal [\%] & $73(91)$ & $64(88)$ & $54(75)$ & $48(73)$ & $37(61)$ & $44(64)$ & $55(68)$ \\
\hline pre-diabetic [\%] & $24(6)$ & $30(6)$ & $29(9)$ & $35(10)$ & $45(21)$ & $40(20)$ & $36(23)$ \\
\hline diabetic [\%] & 3 & 6 & 16 & 17 & 18 & 16 & 9 \\
\hline undiagnosed diab. FPG [\%] & 100 & 33 & 82 & 58 & 50 & 67 & 50 \\
\hline Dysglycemia & $27(9)$ & $36(12)$ & $45(15)$ & $52(27)$ & $63(39)$ & $56(26)$ & $47(31)$ \\
\hline $\mathrm{HbA} 1 \mathrm{c}[\%(\mathrm{mmol} / \mathrm{mol}]$ & $\begin{array}{c}5.5(37) \\
5.2(33) ; 5.8(40)\end{array}$ & $\begin{array}{c}5.6(38) \\
5.3(34) ; 5.9(41)\end{array}$ & $\begin{array}{c}5.7(39) \\
5.3(34) ; 6.1(43)\end{array}$ & $\begin{array}{c}5.8(40) \\
5.3(34) ; 6.1(43)\end{array}$ & $\begin{array}{c}5.8(40) \\
5.6(38) ; 6.3(45)\end{array}$ & $\begin{array}{c}5.9(41) \\
5.6(38) ; 6.5(48)\end{array}$ & $\begin{array}{c}5.8(40) \\
5.6(38) ; 6.2(44)\end{array}$ \\
\hline $\begin{array}{l}\text { Systolic blood pressure } \\
\text { [mmHg] }\end{array}$ & $\begin{array}{c}118.5 \\
108.5 ; 128.3\end{array}$ & $\begin{array}{c}122.5 \\
112 ; 131.8\end{array}$ & $\begin{array}{c}125.0 \\
114.5 ; 135.5\end{array}$ & $\begin{array}{c}126.0 \\
117.0 ; 143.0\end{array}$ & $\begin{array}{c}131.0 \\
120.3 ; 146.0\end{array}$ & $\begin{array}{c}139.0 \\
126.0 ; 152.5\end{array}$ & $\begin{array}{c}136.0 \\
121.8 ; 150.5\end{array}$ \\
\hline $\begin{array}{l}\text { Diastolic blood pressure } \\
{[\mathrm{mmHg}]}\end{array}$ & $\begin{array}{c}81.0 \\
77.0 ; 87.8\end{array}$ & $\begin{array}{c}86.0 \\
80.0 ; 91.0\end{array}$ & $\begin{array}{c}84.0 \\
78.5 ; 91.0\end{array}$ & $\begin{array}{c}87.0 \\
81.0 ; 96.0\end{array}$ & $\begin{array}{c}90.0 \\
82.0 ; 96.8\end{array}$ & $\begin{array}{c}86.0 \\
79.5 ; 96.0\end{array}$ & $\begin{array}{c}89.0 \\
78.9 ; 97.0\end{array}$ \\
\hline \multicolumn{8}{|c|}{ Table 4 ctd.: } \\
\hline Hypertension type I [\%] & 12 & 10 & 12 & 14 & 25 & 35 & 23 \\
\hline Hypertension type II [\%] & 0 & 2 & 4 & 9 & 9 & 9 & 9 \\
\hline Hypertension type III [\%] & 0 & 4 & 0 & 7 & 8 & 5 & 4 \\
\hline Overall hypertension [\%] & 12 & 16 & 16 & 30 & 42 & 49 & 36 \\
\hline
\end{tabular}

Footnote: If not otherwise specified, data are expressed as median and interquartile range; waist circumference is presented as mean and SD; glycemic status based on fasting plasma glucose (FPG) is shown using American Diabetes Association (ADA) and World Health Organization (WHO, shown in parantheses) criteria; dysglycemia was defined by $F P G \geq 5.6 \mathrm{mmol} / \mathrm{L}(A D A)$ or $\geq 6.1 \mathrm{mmol} / \mathrm{L}(\mathrm{WHO})$; HbA1c is shown using ADA criteria; hypertension was defined by having at least one value in stage I, II, or III according to American Heart Association criteria.

Table 4: Anthropometric and medical data within different age groups of screened participants. 
Citation: Ludwig C, Streicher M, Habicht SD, Swai ME, Krawinkel MB (2017) Targeted screening reveals high numbers of prediabetes and diabetes mellitus in Moshi, Tanzania. J Diabetes Metab 8: 720. doi: 10.4172/2155-6156.1000720

Page 6 of 9

\begin{tabular}{|c|c|c|c|c|c|c|}
\hline $\begin{array}{ll}\text { Group } & \text { Health indicator } \\
\end{array}$ & Normal $n=190$ & $\begin{array}{c}\text { Pre-diabetic } \\
\mathrm{n}=131\end{array}$ & Diabetic $n=52$ & $\begin{array}{c}\text { Diagnosed } \\
\text { diabetes } n=20\end{array}$ & $\begin{array}{l}\text { Undiagnosed } \\
\text { diabetes } n=32\end{array}$ & $\begin{array}{l}\text { Treated diabetes } \\
n=13\end{array}$ \\
\hline Age [years] & $\begin{array}{c}45.0 \\
38.0 ; 53.0\end{array}$ & $\begin{array}{c}49.0 \\
42.0 ; 54.0\end{array}$ & $\begin{array}{c}49.0 \\
43.3 ; 54.0\end{array}$ & $\begin{array}{c}50.0 \\
45.0 ; 54.0\end{array}$ & $\begin{array}{c}47.0 \\
43.0 ; 54.0\end{array}$ & $\begin{array}{c}53.0 \\
47.5 ; 56.0\end{array}$ \\
\hline Body mass index $\left[\mathrm{kg} / \mathrm{m}^{2}\right]$ & $\begin{array}{c}29.8 \\
28.1 ; 32.3\end{array}$ & $\begin{array}{c}30.2 \\
28.1 ; 32.1\end{array}$ & $\begin{array}{c}30.4 \\
28.6 ; 31.9\end{array}$ & $\begin{array}{c}30.3 \\
28.4 ; 32.4\end{array}$ & $\begin{array}{c}30.4 \\
29.0 ; 31.8\end{array}$ & $\begin{array}{c}30.2 \\
28.0 ; 32.2\end{array}$ \\
\hline Diabetic family member [\%] & 22 & 22 & 54 & 80 & 38 & 92 \\
\hline Waist circumference $[\mathrm{cm}]$ & $92.5(6.9)$ & $95.5(7.1)$ & $97.0(6.3)$ & $97.8(6.7)$ & $96.5(6.0)$ & $97.4(7.9)$ \\
\hline Fasting plasma glucose [mmol/L] & $\begin{array}{c}5.1 \\
4.7 ; 5.3\end{array}$ & $\begin{array}{c}5.9 \\
5.7 ; 6.3\end{array}$ & $\begin{array}{c}9.2 \\
7.4 ; 13.5\end{array}$ & $\begin{array}{c}12.4 \\
8.6 ; 17.8\end{array}$ & $\begin{array}{c}8.0 \\
7.3 ; 14.1\end{array}$ & $\begin{array}{c}12.2 \\
7.5 ; 18.2\end{array}$ \\
\hline HbA1c [\% (mmol/mol)] & $\begin{array}{l}5.6(38) \\
5.3(34) \\
5.8(40)\end{array}$ & $\begin{array}{l}5.8(40) \\
5.5(37) \\
6.1(43)\end{array}$ & $\begin{array}{l}7.7(61) \\
6.6(49) \\
9.8(84)\end{array}$ & $\begin{array}{l}9.0(75) \\
7.7(61) \\
10.1(87)\end{array}$ & $\begin{array}{l}6.8(51) \\
6.3(45) \\
8.4(68)\end{array}$ & $\begin{array}{l}8.5(69) \\
6.3(45) \\
10.1(87)\end{array}$ \\
\hline Systolic blood pressure[mmHg] & $\begin{array}{c}123.5 \\
114.0 ; 137.3\end{array}$ & $\begin{array}{c}130.0 \\
120.0 ; 144.0\end{array}$ & $\begin{array}{c}134.0 \\
123.0 ; 155.5\end{array}$ & $\begin{array}{c}133.5 \\
122.3 ; 152.8\end{array}$ & $\begin{array}{c}135.0 \\
123.5 ; 170.5\end{array}$ & $\begin{array}{c}134.0 \\
123.8 ; 157.5\end{array}$ \\
\hline \multicolumn{7}{|l|}{ Table 5 ctd.: } \\
\hline $\begin{array}{r}\text { Group } \\
\text { Health indicator }\end{array}$ & $\begin{array}{c}\text { Normal } \\
n=190\end{array}$ & $\begin{array}{l}\text { Pre-diabetic } \\
\quad n=131\end{array}$ & $\begin{array}{l}\text { Diabetic } \\
n=52\end{array}$ & $\begin{array}{l}\text { Diagnosed diabetes } \\
n=20\end{array}$ & $\begin{array}{l}\text { Undiagnosed } \\
\text { diabetes } \\
n=32\end{array}$ & $\begin{array}{l}\text { Treated diabetes } \\
\qquad n=13\end{array}$ \\
\hline Diastolic blood pressure [mmHg] & $\begin{array}{c}84.0 \\
78.0 ; 91.0\end{array}$ & $\begin{array}{c}89.0 \\
80.0 ; 96.0\end{array}$ & $\begin{array}{c}90.0 \\
84.3 ; 97.8\end{array}$ & $\begin{array}{c}88.0 \\
80.5 ; 95.3\end{array}$ & $\begin{array}{c}95.5 \\
85.1 ; 99.5\end{array}$ & $\begin{array}{c}90.0 \\
80.0 ; 98.5\end{array}$ \\
\hline Hypertension type I [\%] & 20 & 27 & 31 & 25 & 19 & 23 \\
\hline Hypertension type II [\%] & 7 & 12 & 10 & 10 & 9 & 15 \\
\hline Hypertension type III [\%] & 6 & 8 & 14 & 5 & 19 & 8 \\
\hline Overall hypertension [\%] & 33 & 47 & 55 & 40 & 47 & 46 \\
\hline
\end{tabular}

Table 5: Health indicators among the different groups defined by glycemic status (according to ADA criteria)

If not otherwise specified, data are expressed as median and interquartile range; waist circumference is presented as mean and SD; hypertension was defined by having at least one value in stage I, II, or III according to American Heart Association criteria.

\begin{tabular}{|c|c|c|c|c|c|c|c|c|c|}
\hline \multirow{2}{*}{$\begin{array}{l}\text { Variable } \\
\text { Predictor }\end{array}$} & \multicolumn{2}{|c|}{ Fasting plasma glucose } & \multicolumn{2}{|c|}{ HbA1c } & \multicolumn{2}{|c|}{ Systolic blood pressure } & \multicolumn{2}{|c|}{ Diastolic blood pressure } & \multirow[t]{2}{*}{ Overall $\mathbf{R}^{2}$} \\
\hline & Coefficient $^{c}$ & $\mathrm{p}$ & Coefficient $^{c}$ & $\mathrm{p}$ & Coefficient $^{c}$ & $\mathrm{p}$ & Coefficient $^{\circ}$ & $\mathrm{p}$ & \\
\hline $\mathrm{Age}^{\mathrm{a}}$ & 0.140 & 0.003 & 0.177 & 0.000 & 0.339 & 0.000 & 0.195 & 0.001 & \\
\hline Age_sqa & 0.142 & 0.001 & 0.098 & 0.012 & 0.019 & 0.765 & 0.064 & 0.298 & \\
\hline $\mathrm{R}^{2}$ & \multicolumn{2}{|c|}{0.045} & \multicolumn{2}{|c|}{0.048} & \multicolumn{2}{|c|}{0.119} & \multicolumn{2}{|c|}{0.052} & 0.184 \\
\hline $\begin{array}{l}\text { Waist } \\
\text { circumferenceb }\end{array}$ & 0.219 & 0.000 & 0.221 & 0.000 & 0.114 & 0.047 & 0.123 & 0.029 & \\
\hline Waist CF_sq ${ }^{b}$ & 0.010 & 0.834 & 0.047 & 0.309 & 0.059 & 0.325 & 0.107 & 0.052 & \\
\hline $\mathrm{R}^{2}$ & \multicolumn{2}{|c|}{0.093} & \multicolumn{2}{|c|}{0.086} & \multicolumn{2}{|c|}{0.134} & \multicolumn{2}{|c|}{0.078} & 0.248 \\
\hline Body mass index ${ }^{b}$ & 0.142 & 0.003 & 0.130 & 0.005 & 0.008 & 0.893 & 0.026 & 0.682 & \\
\hline $\begin{array}{l}\text { Body mass index } \\
\text { sq }^{\mathrm{b}}\end{array}$ & 0.162 & 0.000 & 0.091 & 0.051 & 0.014 & 0.798 & 0.061 & 0.281 & \\
\hline $\mathrm{R}^{2}$ & \multicolumn{2}{|c|}{0.075} & \multicolumn{2}{|c|}{0.064} & \multicolumn{2}{|c|}{0.119} & \multicolumn{2}{|c|}{0.058} & 0.230 \\
\hline
\end{tabular}

Table 6: Results of the non-linear model using seemingly unrelated regression, $n=291$ for predictor age and body mass index, $n=290$ for predictor waist circumference.

\begin{tabular}{|c|c|c|}
\hline & Fasting plasma glucose & HbA1c \\
\hline $\mathrm{HbA}_{1 \mathrm{c}}$ & 0.847 & 0.205 \\
\hline Systolic blood pressure & 0.264 & 0.150 \\
\hline Diastolic blood pressure & 0.197 & 0.804 \\
\hline
\end{tabular}

Table 7: Correlations of dependent variables (Spearman's rho) controlled for age and sex, all $p<0.05$.

versa, another study detected a high BMI as a predictor for a sedentary lifestyle [29]. Regarding increased BMI and a trend toward nonagricultural jobs in Tanzania [30], possibilities to engage in physical activity outside work should be introduced.

In the current study, BMI increased with age until 40-49 years, similar to results reported in the TDHS [26]. This age trend was also found for systolic and diastolic BP and diastolic BP peaked at the age group of 40-49. BP was positively correlated with BMI, stronger for diastolic than systolic BP. Other studies have also demonstrated ageand BMI-related increases in systolic and diastolic BP [31] or both as independent predictors for arterial hypertension [32]. Overall, 30\% of prescreened participants were classified as hypertensive, which is similar to the WHO's age-standardized estimate of $29 \%$ [1]. The majority was unaware of their hypertensive BP values, which was also seen in other settings [8] and requires attention in public health programs for preventing cardiovascular diseases.

Although the screening sample was not representative for the population and not diagnostic, the high rates of pre-diabetic and diabetic FPG values (35\% and $14 \%$, respectively) and high $\mathrm{HbA1c}$ values ( $42 \%$ and $16 \%$, respectively), according to ADA criteria, are of 
concern.

In a multiethnic study of pre-diabetes and diabetes mellitus rates were lower compared to the current setting: pre-diabetes (IFG according to ADA criteria) and diabetes prevalences were $10 \%$ and $14 \%$ in South Africa, $18 \%$ and $14 \%$ in Southern Cone of Latin America, $17 \%$ and $10 \%$ in Peru, and $4 \%$ and $19 \%$ in South Asia, respectively [33]. In another study, rates of pre-diabetes defined as IFG were $28 \%$ in nonHispanic black individuals, $27 \%$ in non-Hispanic white individuals, and $29 \%$ in Hispanic individuals [34]

Around $60 \%$ of the probands in Tanzania were unaware of their diabetic FPG levels, which was lower than the estimate of $67 \%$ in SubSaharan Africa [4]. In other studies, rates of undiagnosed diabetes ranged from $18 \%$ to $62 \%[8,35,36]$. The overall high prevalence of diabetes among the screened sample can be explained by the observation that a high number of diabetics came to the screening with the assumption they were coming to a new diabetes clinic offering free measurements. In the subgroup of treated diabetes patients, median HbAlc was $8.5 \%(69 \mathrm{mmol} / \mathrm{mol})$, higher than the recommended target level of $7 \%(65 \mathrm{mmol} / \mathrm{mol})$ for glycemic control among diabetes patients [12]. In addition, HbAlc levels among people with diabetic FPG (treated and untreated; known and unknown) were high. This, together with the high levels of hypertension, indicates that interventions are urgent to prevent complications among people with diabetes mellitus in Tanzania.

According to $\mathrm{WHO}$ criteria, prevalence of pre-diabetes was $12 \%$. As seen in other studies [36- 39], pre-diabetic prevalence rates varied between $\mathrm{ADA}$ and $\mathrm{WHO}$ criteria. In the current study, applying $\mathrm{ADA}$ criteria resulted in a 2.7 times higher prevalence rate than WHO criteria. The WHO had previously stated that lowering the threshold for IFG from $6.1 \mathrm{mmol} / \mathrm{L}$ to $5.6 \mathrm{mmol} / \mathrm{L}$ would result in a higher rate of pre-diabetes with a lack of evidence for better health outcomes [40]. Due to the tailored screening of people with higher BMI and age, as well as differences in IFG and IGT status, the pre-diabetes prevalence of $35 \%$ according to ADA-criteria was more than three times higher in this study than the reported national prevalence of $10.3 \%$ defined by IGT [7]. People with IFG may not necessarily have IGT, and vice versa [41]. In a study by Zhang et al., isolated IFG was prevalent among $27 \%$ of study participants, whereas $5.1 \%$ had isolated IGT and $10.3 \%$ had both IFG and IGT [34]. Another study by Chilelli et al., found isolated IFG in $27.1 \%$, isolated IGT in $6.8 \%$, and both in $4.6 \%$ [42]. Both applied ADA cut-off values for IFG, which may explain the higher rates of prediabetes based on FPG than based on glucose tolerance.

Probands with diabetic glucose levels showed the highest concordance between $\mathrm{HbAlc}$ and FPG, although the overall Krippendorff's a was low (0.351). In a cross-sectional study at a primary care setting in Spain [43], HbAlc measurements revealed a significantly lower diabetes prevalence $(3.2 \%)$ compared to 2-hour OGTT (9.2\%), but was similar to FPG (3.1\%). In a population-based survey in a rural district of Uganda, diabetes prevalence rates were $4.8 \%$ according to FPG and $11.3 \%$ according to HbAlc. Despite the low agreement between $\mathrm{HbAlc}$ and FPG, they detected a high agreement among negatives (normo-glycemic FPG and normal HbA1c) [37]. Specifying universal cut-off points for HbAlc may be difficult due to ethnic differences, with higher levels observed among people of African origin [44, 45], as well as other influencing factors [46]. However, it has been argued that $\mathrm{HbAlc}$ is a valid predictor for diabetes, including undiagnosed cases, but should not be used to identify prediabetes [47].
Regarding risk factors for increased glucose or BP values, the current study showed similar results as other assessments with WC and BMI being predictors for FPG and BP. The association between WC and dependent variables was linear, whereas it was non-linear for BMI. The current study had an upper BMI limit of $35 \mathrm{~kg} / \mathrm{m}^{2}$ whereas a higher limit would be needed to assess a non-linear association between BMI and FPG and BP. In a study in Brazil, mean BMI did not differ between prediabetic or normoglycemic groups, but WC was significantly higher among pre-diabetics than among normoglycemic participants [48]. In another study, obese people were two times more affected by dysglycemia than normal-weight people [36]. The measurement of WC as a low cost and noninvasive method might serve as a good screening tool to assess risk for dysglycemia.

In the current study, there was no difference in BP or glycemic status between alcohol consumers and non-consumers. Overall, alcohol consumption in the study population was similar to national data [1]. Smoking rates were considerably lower with $6 \%$ and $0.4 \%$ among men and women, compared to national data of $28 \%$ and $4 \%$, respectively [1]. Thus, no association with tobacco use could be found. A study by Mayega found no association of abnormal glucose regulation with sex, age group, hypertension, tobacco use, or harmful alcohol use [36].

Whether screening for diabetes will be feasible is to be discussed among health and policy institutions. It has been argued that screening for diabetes is not feasible, as it does not meet all criteria for disease screening [13] as defined by WHO [15]. One major criticism is that screening should only be done if medical treatment is available [14, 15]. Assessments indicate that there are insufficient medical supplies and treatment facilities in Tanzania [49-51]. However, as progression of pre-diabetes to type 2 diabetes mellitus and related complications might be modified with lifestyle changes $[52,53]$, especially increased physical activity, a screening of pre-diabetes or diabetes may be worthwhile.

Promotion of a healthy lifestyle and related activities should be strived for generally, but could also be conducted with the help of screening, as people might be more motivated to change eating and physical activity habits after they know their own health status. In the current setting, FPG significantly dropped among some participants from the time point of the screening to the baseline measurement of the following intervention study. During the screening process, counseling on a healthy lifestyle was provided to participants if requested. The blood glucose measurement together with counseling may already have led to a change in behavior and a drop in FPG. Nevertheless, in regard to the region's high levels of elevated BP and glucose levels, health promotion strategies should be established in addition to screening activities.

\section{Limitations}

The current study did not assess glucose tolerance. Measurement of glucose tolerance is not always feasible in resource-poor or work settings, as it is cumbersome and time consuming, especially in a screening setting $[37,54]$. In the current screening, which had no diagnostic character, the measurement of FPG to define glycemic status was quick and easily administered by health staff. However, Yudkin and Montori (2014) expressed concerns about the new ADA cut-offs and the subsequent increase in pre-diabetes diagnoses, as well as the overall concept of categorizing people as pre-diabetic. They argue that it diverts attention from high risk people or diabetic individuals who need medical attention [55]. Rates of pre-diabetes may be even higher when an HbAlc cut-off of 5.7 to $6.4 \%$ is applied [55]. This was 
Citation: Ludwig C, Streicher M, Habicht SD, Swai ME, Krawinkel MB (2017) Targeted screening reveals high numbers of prediabetes and diabetes mellitus in Moshi, Tanzania. J Diabetes Metab 8: 720. doi: 10.4172/2155-6156.1000720

also the case in the current screening in which $42 \%$ of participants had pre-diabetic $\mathrm{HbA1c}$ values compared to $35 \%$ or $12 \%$ having pre diabetic IFG levels according to ADA or WHO criteria, respectively. These results were confirmed in other studies reporting higher rates of elevated FPG using HbA1c than FPG [37] or 2-hour OGTT [56]. However, some other studies showed comparable rates [43], and some missed cases or found lower rates when ADA's recommended cut-offs for HbA1c were applied [57, 58]. Because the screening was tailored to include overweight and obese people, conclusions cannot be drawn about the overall population. Most measurements were only performed once, and there was no measurement of IGT to compare with FPG levels. The measurement of FPG was choosen as an easy method of assessing glycemic status in this setting. The point-of-care device for the measurements did not require continous access to electricity or extensive training of health staff. Zhao et al. demonstrated that the measurement of glycemic status using a capillary blood sample is a feasible screening method in a low-resource setting [59]. If FPG cannot be measured, RBG may be measured instead. Studies have demonstrated that a single RBG measurement of $>100 \mathrm{mg} / \mathrm{dL}$ [60] or $>125 \mathrm{mg} / \mathrm{dL}$ [61] were good predictors of diabetes.

\section{Conclusions}

The current procedure used to recruit pre-diabetic participants for a dietary intervention study led to an enrollment rate of $16 \%$ among people with a BMI of $27-35 \mathrm{~kg} / \mathrm{m}^{2}$ and an age of $30-65$ years. The low concordance between FPG and $\mathrm{HbAlc}$ needs further investigation, as well as the discrepancy between ADA and WHO definitions of IFG. Identified risk factors for increased FPG were age, WC, BMI, and having a family member with diabetes. During the pre-screening and screening phases, high rates of obesity, undiagnosed hypertension, and undiagnosed diabetes were found which require an extension of existing health programs in scope and capacity. The visited institutions and companies were all receptive to health issues, and this attitude could be utilized for health promotion and education on prevention. This study was not designed as a population screening for diabetes, but did detect a high number of undiagnosed diabetes. Further research may focus on analyzing costs and benefits of screening for chronic non-communicable diseases in that region of Tanzania.

\section{Acknowledgements}

The authors are gratefull for the cooperation of the staff of the Kilimanjaro Clinical Research Institute and the diabetes clinic of the Kilimanjaro Christian Medical Centre as well as for the support of Dr. Johannes Herrmann, Giessen, Germany, in the processing of the data.

\section{References}

1. WHO (2014) Global status report on noncommunicable diseases 2014: attaining the nine global noncommunicable diseases targets; a shared responsibility. Geneva, Switzerland

2. Popkin BM, Adair LS, Ng SW (2012) Global nutrition transition and the pandemic of obesity in developing countries. Nutr Rev 70: 3-21.

3. Boutayeb A, Boutayeb S (2005) The burden of non communicable diseases in developing countries. Int J Equity Health 4: 2.

4. IDF (2015) International Diabetes Federation. IDF Diabetes Atlas 7th edn Brussels, Belgium.

5. Levitt NS (2008) Diabetes in Africa: epidemiology, management and healthcare challenges. Heart 94: 1376-1382.

6. IDF (2012) International Diabetes Federation. IDF Diabetes Atlas, 5th edn. Brussels, Belgium.

7. IDF (2013) International Diabetes Federation. IDF Diabetes Atlas 6th edn. Brussels, Belgium.
8. Kavishe B, Biraro S, Baisley K, Vanobberghen F, Kapiga S, et al. (2015) High prevalence of hypertension and of risk factors for non-communicable diseases (NCDs): a population based cross-sectional survey of NCDS and HIV infection in Northwestern Tanzania and Southern Uganda. BMC Med 13: 126.

9. Aspray TJ, Mugusi F, Rashid S, Whiting D, Edwards R, et al. (2000) Rural and urban differences in diabetes prevalence in Tanzania: the role of obesity, physical inactivity and urban living. Trans R Soc Trop Med Hyg 94: 637-44.

10. WHO (1999) Definition, diagnosis and classification of diabetes mellitus and its complications. Organization, Department of Noncommunicable Disease Surveillance, Geneva.

11. Association AD (2010) Diagnosis and Classification of Diabetes Mellitus Diabetes Care 33: S62-69.

12. Association AD (2014) Standards of medical care in diabetes--2014. Diabetes Care 37: S14-80.

13. Association AD (2002) Screening for Diabetes. Diabetes Care 25: s21-24.

14. National Cancer Control Policy Australia (2015) Principles of 503 screening. Cancer Council Australia

15. Wilson JMG, Junger G (1968) Principles and practice of screening for disease. Geneva, Switzerland: World Health Organization.

16. National Bureau of Statistics, Ministry of Finance (2013) Tanzania in Figures 2012 Dar es Salaam, Tanzania.

17. Moshi Municipality Council (2012) GIM International.

18. Manta Ray Media (2015)

19. WHO Expert Consultation (2004) Appropriate body-mass index for Asian populations and its implications for policy and intervention strategies. Lancet 363: 157-163.

20. WHO (2015) Global Database on Body Mass Index.

21. AHA (2015) Understanding blood pressure readings.

22. Cogill B (2003) Anthropometric Indicators Measurement Guide. Food and Nutrition Technical Assistance Project, Academy for Educational Development, Washington, D.C.

23. WHO STEPS Surveillance (2008) Section 3: Guide to Physical Measurements (Step 2). Geneva, Switzerland (Part 3: Training and Practical Guides).

24. Hayes AF, Krippendorff $\mathrm{K}$ (2007) Answering the call for a standard reliability measure for coding data. Commun Methods Meas 1: 77-89.

25. Wooldridge JM (2010) Econometric analysis of cross section and panel data 2nd ed. Cambridge, Massachusetts, USA: MIT Press 1064p.

26. National Bureau of Statistics, ICF Macro (2011) Tanzania Demographic Health Survey 2010. Dar es Salaam, Tanzania, Calverton, Maryland, USA.

27. Dixon JB (2010) The effect of obesity on health outcomes. Mol Cell Endocrinol 316: $104-108$

28. Agrawal P, Gupta K, Mishra V, Agrawal S (2013) Effects of 543 sedentary lifestyle and dietary habits on body mass index change among adult women in India: findings from a follow-up study. Ecol Food Nutr 52: 387-406.

29. Mortensen LH, Siegler IC, Barefoot JC, Grønbaek M, Sørensen TI (2006) Prospective associations between sedentary lifestyle and BMI in midlife. Obes Silver Spring Md. 14: 1462-1471.

30. International Labour Office (2009) Decent work country profile: Tanzania (mainland). Geneva, Switzerland.

31. Mungreiphy NK, Kapoor S, Sinha R (2011) Association between BMI, Blood Pressure, and Age: Study among Tangkhul Naga Tribal Males of Northeast India. J Anthropol.

32. Gebreselassie KZ, Padyab M (2015) Epidemiology of Hypertension Stages in Two Countries in Sub-Sahara Africa: Factors Associated with Hypertension Stages. Int J Hypertens.

33. Shen J, Kondal D, Rubinstein A, Irazola V, Gutierrez L, et al. (2016) A Multiethnic Study of Pre-Diabetes and Diabetes in LMIC. Glob Heart 11: 61-70.

34. Zhang Y, Hu G, Zhang L, Mayo R, Chen L (2015) A novel testing model for opportunistic screening of pre-diabetes and diabetes among U.S. adults. PLoS One 10: e0120382. 
Citation: Ludwig C, Streicher M, Habicht SD, Swai ME, Krawinkel MB (2017) Targeted screening reveals high numbers of prediabetes and diabetes mellitus in Moshi, Tanzania. J Diabetes Metab 8: 720. doi: 10.4172/2155-6156.1000720

35. Heianza Y, Arase Y, Fujihara K, Tsuji H, Saito K, et al. (2012) Screening for pre-diabetes to predict future diabetes using various cut-off points for $\mathrm{HbA} 1 \mathrm{c}$ and impaired fasting glucose: the Toranomon Hospital Health Management Center Study 4 (TOPICS 4). Diabet Med 29: e279-285.

36. Mayega RW, Guwatudde D, Makumbi F, Nakwagala FN, Peterson S, et al (2013) Diabetes and Pre-Diabetes among Persons Aged 35 to 60 Years in Eastern Uganda: Prevalence and Associated Factors. Plos One 8: e72554.

37. Mayega RW, Guwatudde D, Makumbi FE, Nakwagala FN, Peterson S, et al. (2014) Comparison of fasting plasma glucose and haemoglobin A1c point-of care tests in screening for diabetes and abnormal glucose regulation in a rural low income setting. Diabetes Res Clin Pract 104: 112-120.

38. Bao C, Zhang D, Sun B, Lan L, Cui W, et al. (2015) Optimal Cut-Off Points of Fasting Plasma Glucose for Two-Step Strategy in Estimating Prevalence and Screening Undiagnosed Diabetes and Pre-Diabetes in Harbin, China. Plos One 10: e0119510.

39. Xu Y, Wang L, He J, Bi Y, Li M, et al. (2013) Prevalence and control of diabetes in Chinese adults. JAMA 310: 948-959.

40. World Health Organization (2013) WHO | About diabetes.

41. Perreault L, Færch K (2014) Approaching pre-diabetes. J Diabetes Complications 28: 226-233.

42. Chilelli NC, Cosma C, Ragazzi E, Burlina S, Zaninotto M, et al. (2014) Screening with $\mathrm{HbA} 1 \mathrm{c}$ identifies only one in two individuals with diagnosis of prediabetes at oral glucose tolerance test: findings in a real-world Caucasian population. Acta Diabetol 51: 875-882.

43. Costa B, Barrio F, Pinol JL, Cabre JJ, Mundet X, et al. (2013) Shifting from glucose diagnosis to the new $\mathrm{HbA1c}$ diagnosis reduces the capability of the Finnish Diabetes Risk Score (FINDRISC) to screen for glucose abnormalities within a real-life primary healthcare preventive strategy. BMC Med 11: 45.

44. Selvin E, Steffes MW, Ballantyne CM, Hoogeveen RC, Coresh J, et al (2011) Racial differences in glycemic markers: a cross-sectional analysis of community-based data. Ann Intern Med 154: 303-309.

45. Ziemer DC, Kolm P, Weintraub WS, Vaccarino V, Rhee MK, et al. (2010) Glucose-independent, black-white differences in hemoglobin A1c levels: a cross sectional analysis of 2 studies. Ann Intern Med. 152: 770-777.

46. Dubowitz N, Xue W, Long Q, Ownby JG, Olson DE, et al. (2014) Aging is associated with increased $\mathrm{HbA1c}$ levels, independently of glucose levels and insulin resistance, and also with decreased $\mathrm{HbA} 1 \mathrm{c}$ diagnostic specificity. Diabet Med 31: 927-935.

47. WHO (2011) Use of glycated haemoglobin (HbA1c) in diagnosis of diabetes mellitus: abbreviated report of a WHO consultation.

48. Franco LJ, Dal Fabbro AL, Martinez EZ, Sartorelli DS, Silva AS, et al. (2014) Performance of glycated haemoglobin $(\mathrm{HbA} 1 \mathrm{c})$ as a screening test for diabetes and impaired glucose tolerance (IGT) in a high risk population-The Brazilian Xavante Indians. Diabetes Res Clin Pract 106: 337-342.
49. Robertson J, Macé C, Forte G, Joncheere K de, Beran D (2015) Medicines availability for non-communicable diseases: the case for standardized monitoring. Glob Health 11: 18.

50. Peck R, Mghamba J, Vanobberghen F, Kavishe B, Rugarabamu V, et al (2014) Preparedness of Tanzanian health facilities for outpatient primary care of hypertension and diabetes: a cross-sectional survey. Lancet Glob Health 2: e285-292.

51. MOHSW (2012) Dar es Salaam, Tanzania: Ministry of Health and Social Welfare.

52. Burr JF, Rowan CP, Jamnik VK, Riddell MC (2010) The role of physical activity in type 2 diabetes prevention: physiological and practical perspectives. Phys Sportsmed 38: 72-82.

53. Sato Y, Nagasaki M, Kubota M, Uno T, Nakai N (2007) Clinical aspects of physical exercise for diabetes/metabolic syndrome. Diabetes Res Clin Pract 77: S87-91.

54. Anand SS, Razak F, Vuksan V, Gerstein HC, Malmberg K, et al. (2003) Diagnostic Strategies to Detect Glucose Intolerance in a Multiethnic Population. Diabetes Care 26: 290-296.

55. Yudkin JS, Montori VM (2014) The epidemic of pre-diabetes: the medicine and the politics.BMJ 349: g4485.

56. Botana Lopez MA, Lopez Raton M, Tome MA, Fernandez Marino A, Mato Mato JA, et al. (2012) Relationship between glycated hemoglobin and glucose concentrations in the adult Galician population: selection of optimal glycated hemoglobin cut-off points as a diagnostic tool of diabetes mellitus. Endocrino Nutr Soc Espanola Endocrinol Nutr 59: 496-504.

57. Bhansali A, Walia R, Kumar PR, Kiran MR, Shanmugasundar G (2012) Accuracy of glycated haemoglobin in screening for pre-diabetes in Asian Indians-a community survey: the Chandigarh Urban Diabetes Study (CUDS). Diabet Med 29: 1385-1389.

58. Zhou X, Pang Z, Gao W, Wang S, Zhang L, et al. (2010) Performance of an $\mathrm{A} 1 \mathrm{C}$ and fasting capillary blood glucose test for screening newly diagnosed diabetes and pre-diabetes defined by an oral glucose tolerance test in Qingdao, China. Diabetes Care 33: 545-550.

59. Zhao X, Zhao W, Zhang H, Li J, Shu Y, et al. (2012) Fasting capillary blood glucose: An appropriate measurement in screening for diabetes and pre diabetes in low-resource rural settings. J Endocrinol Invest 36: 33-37.

60. Bowen ME, Xuan L, Lingvay I, Halm EA (2015) Random blood glucose: a robust risk factor for type 2 diabetes. J Clin Endocrinol Metab 100: 1503-1510.

61. Ziemer DC, Kolm P, Foster JK, Weintraub WS, Vaccarino V, et al. (2008) Random plasma glucose in serendipitous screening for glucose intolerance: screening for impaired glucose tolerance study 2. J Gen Intern Med 23 528-535. 